\title{
The Time Value of Carbon and Carbon Storage: Clarifying the terms and the policy implications of the debate
}

\author{
LIZ MARSHALL (ERS/USDA) ${ }^{1}$, ALEXIA KELLY (World Resources Institute)
}

This paper presents methodologies for using social cost of carbon estimates to address the value of temporarily stored carbon and the implications of that value in the context of biological offsets and life-cycle analyses of the GHG content of biofuels. The paper is designed to advance the dialogue in these areas by clarifying the concepts involved and moving discussion beyond theoretical debate to exploring the potential policy applications of actual estimates.

World Resources Institute Working Papers contain preliminary research, analysis, findings, and recommendations. They are circulated to stimulate timely discussion and critical feedback and to influence ongoing debate on emerging issues. Most working papers are eventually published in another form and their content may be revised.

Suggested citation: Marshall, Liz, and Alexia Kelly. 2010. “The Time Value of Carbon and Carbon Storage: Clarifying the terms and the policy implications of the debate.” WRI Working Paper. World Resources Institute, Washington, DC. 23 pp. Available online at http://www.wri.org/publications.

\section{EXECUTIVE SUMMARY}

The question of whether there is any value to the temporary storage of carbon is fundamental to climate policy design across a number of arenas, including physical carbon discounting in greenhouse gas accounting, the relative value of temporary carbon offsets, and the value of other carbon mitigation efforts that are known to be impermanent, including deferred deforestation. Quantifying the value of temporary carbon storage depends on a number of assumptions about how the incremental impact (or social cost) of a given ton of carbon emissions is expected to change over time. In 2009, a U.S. government interagency working group was established and assigned the responsibility of calculating social cost of carbon estimates to be used in benefit/cost analysis of regulations impacting carbon dioxide emissions. Those estimates were released in March 2010. This working paper explores what those estimates imply about the value of temporary carbon storage, as well as the implications of those temporary storage values for several critical policy design questions relating to greenhouse gas accounting and biological offsets. This analysis suggests, for instance, that appropriate physical carbon discount rates for carbon accounting may be even lower than the social discount rates often used in intergenerational analyses. In the context of agricultural offsets, the social cost of carbon estimates are used to establish a definition of equivalence between permanent and temporary offsets; equivalence ratios are derived that vary between $\sim 2$ and 30, depending on the discount rate used and the length of the temporary offset contract period.

\section{INTRODUCTION}

Consider the question: Is there any reason to invest in mitigation projects that will capture carbon today and then release an equivalent amount of carbon in 50 years?

October 2010 
This question asks whether there is any value to the temporary storage of carbon. Note that the question excludes many of the common contexts in which concepts of "temporary storage" or "impermanence" are debated. For instance, the question is not relevant to the "risk of reversal" discussion, which focuses on quantifying how the risk of premature release of carbon (i.e., before the end of a contract period) impacts the value and integrity of an offset, as well as on designing mechanisms to prevent (or compensate for) such releases at the national or project scale. This analysis assumes that storage reversal will occur with 100 percent certainty at the end of the project period but, conversely, that the carbon will remain stored for the project duration of 50 years. As posed, the question explores the fundamental issue of whether there is value to storage that is known to be temporary.

This discussion paper explores the issues and implications associated with temporary carbon storage in an attempt to articulate whether or not temporary carbon storage has a value, what the nature of that value is, and how it can be used to inform policy design in a variety of relevant arenas for greenhouse gas (GHG) accounting and climate policy. Specifically, this paper explores the implications of a positive valuation of temporary storage in three contexts: lifecycle GHG accounting for biofuels, agricultural offsets accounting, and deferred emissions from reduced deforestation and forest degradation (REDD) mechanisms.

\section{THE VALUE OF TEMPORARY CARBON STORAGE: CLARIFYING THE TERMS}

While there is no consensus on the matter, several authors have argued in favor of a positive value for temporary storage of carbon. The literature has cited reasons such as:

1. "buying time” for learning, technological advancement and deployment, or capital turnover (Marland et al., 2001);

2. slowing the rise of temperature and therefore delaying the impacts of climate change (Dornburg and Marland, 2008);
3. altering the path of emissions in other ways - smoothing out the path of emissions and avoiding peaks — that allow us to delay impacts (Dornburg and Marland, 2008); and

4. creating potential for temporary storage to become permanent (Chomitz, 2000).

For the moment, this analysis is concerned only with the original question about whether temporary storage has a value in and of itself, and therefore eliminates the last reason from discussion and focuses instead on the first three.

There is a fundamental distinction between the first reason given above and the next two. The second and third reasons both refer to the impacts arising from changing the time path of damages incurred by emissions. The "timepath” argument reasons that if temporarily withholding a unit of emissions changes the path of emissions in a way that delays impacts, then aggregate damages from emissions will go down: "Temporary sinks slow the rise of temperature during their maintenance, and, thus, shorten the time of climate change impacts. In an analysis that 'treats climate-change impacts in any year as equally important,' the cumulative temperature impact will always be favorable for temporary sinks" (Dornburg and Marland, 2008).

According to this argument, the value of temporary storage arises through impacting the cumulative value of damages incurred; if we delay the onset of those damages, the value of damages in aggregate goes down. This type of value to temporary carbon storage would be manifested in a declining social cost of carbon over time. The social cost of carbon (SCC) refers to the cost of the damage done through the emission of a unit of carbon dioxide (Tol, 2008). That value is also, analogously, the value or benefit associated with preventing a unit of carbon dioxide) emissions. ${ }^{2}$ If the social cost of carbon is declining, it means that a unit of emissions will add less to the aggregate damage done by carbon dioxide emissions if it is postponed. In this context, the value of temporary storage derives from the reduced costs associated with delayed or "smoothed" carbon dioxide stock buildup. 
The "buying time" argument for temporary storage value addresses the flip side of the carbon challenge. Rather than addressing how the benefits of reducing emissions change over time with atmospheric stocks and damages inflicted, the value of "buying time" for compliance arises from how the costs of reducing emissions are expected to change over time. This argument asserts that, given that we know we want to reduce greenhouse gas emissions permanently, it may be less costly in the long run to engage in temporary reductions now, and then make those reductions permanent at lower cost later, when new technology has been developed or can be adopted in conjunction with natural capital turnover cycles. The value of the temporary reductions in those cases derives from the ability to ultimately make permanent reductions more cost-effectively; that value is fundamentally different from the "smoothing" value described above, where temporary reductions themselves carry a value. According to the "buying time" argument, the value of temporary storage derives from the value of delayed investment in permanent storage.

For clarity, we will refer to the values arising from delayed carbon stock damages as the "value of temporary storage," with the assumption that such storage is in fact temporary and ends at the end of the storage project period. In contrast, the value arising from increased flexibility to costeffectively achieve permanent reductions over time will be referred to as the "value of interim storage." In the latter case, the implication is that the path of emissions reduction will remain unbroken, but that the form of that reduction is likely to change from the interim project to a more permanent reduction at some point.

Such a distinction is important because the pathways generating the values are completely different, as are the methods used to estimate them. In the following sections we explore in more detail the complexities of measuring the value of temporary storage, the proxies used to represent them in policy, the policy arenas in which some of these debates are playing out, and the policy implications of the uncertainty associated with those measurements. An in-depth exploration of the value of interim storage is not covered in this working paper.

\section{THE VALUE OF TEMPORARY STORAGE: THE SOCIAL COST OF CARBON}

Rising atmospheric carbon dioxide concentrations have been implicated in costly geophysical changes ranging from rising sea level to changing precipitation patterns, including increased frequency of catastrophic weather events such as hurricanes and drought (IPCC, 2007). Such findings support the general conclusion that the social cost of carbon is positive, that is, that there is a cost to society associated with the emissions of greenhouse gases. There are therefore potential benefits to be derived from curtailing carbon emissions and from policies that impose or incentivize such constraints. ${ }^{3}$ No consensus exists, however, about what the precise value of that social cost figure is (Tol, 2008). An extensive history of economic analysis on the topic has illuminated the complexities of the issue but has failed to arrive at a consensus value due to the significant levels of uncertainty surrounding the derivation of actual estimates.

A significant portion of that complexity arises from the dynamics associated with carbon emissions and impacts. Carbon's persistence in the atmosphere, for instance, means that evaluating the full impact of a current unit of emissions requires an understanding of the present damages associated with an additional unit of carbon in the atmosphere, as well as how those damages will change over the lifetime of that unit in the atmosphere.

There are two relevant time horizons in the calculation and use of social cost of carbon estimates in evaluating the greenhouse gas impacts of a project or product (Marshall, 2009). The first, the "impact horizon," refers to the period of time over which warming impacts occur when a unit of carbon is emitted. The second relevant time horizon is the "project horizon," or the period of time over which a project or regulation results in changes of emissions and emissions timing (Figure 1). In the context of greenhouse gas accounting at the project or product level, it is often necessary to aggregate carbon emissions over time in determining net carbon impacts. The greenhouse gas emissions changes associated with a project, especially those involving land-use change, often occur over a long period of time. Any attempt to compare emissions over 
Figure 1 | There are two distinct rounds of discounting involved in the calculation and use of social cost of carbon estimates (represented by A and B).

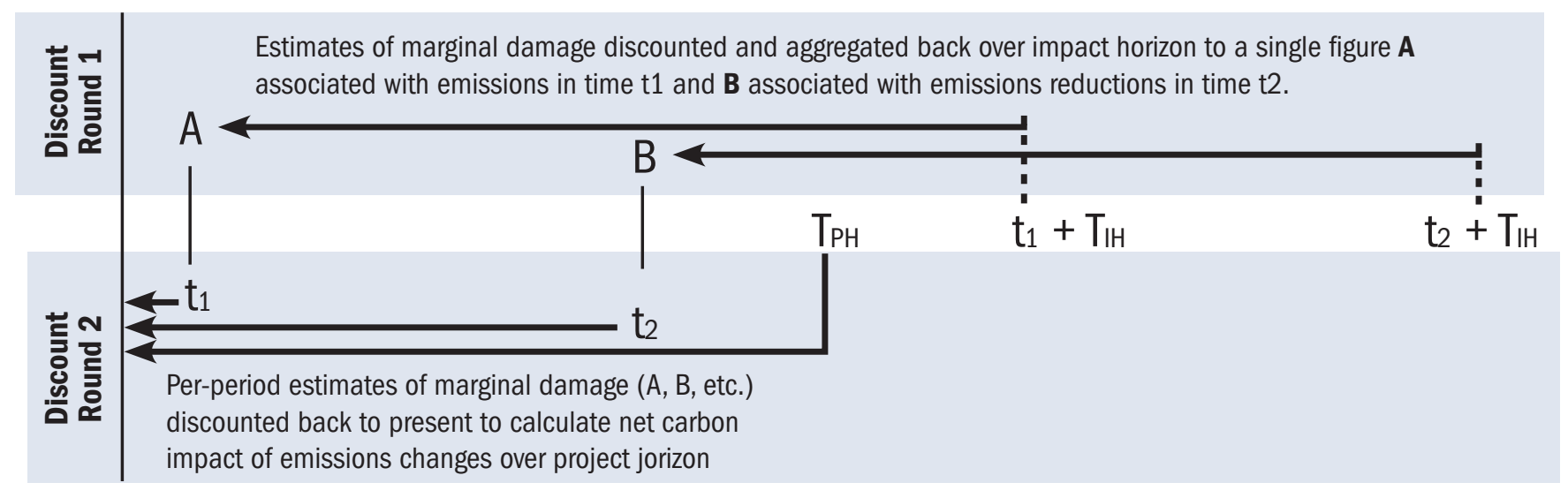

time, in order to weight and aggregate them according to some measure of relative impact, requires an understanding of how the value of the damage caused by a unit of emissions in the future will compare to the value of damage caused by a unit of emissions today.

Figure 1 illustrates a case where the social cost of carbon is calculated for emissions in two different time periods, which are denoted $t_{1}$ and $t_{2}$. The social costs of carbon assigned to the emissions, which are denoted $\mathrm{A}$ and $\mathrm{B}$, respectively, are calculated by estimating and aggregating emissions impacts over the "impact horizon" (denoted $\mathrm{T}_{\mathrm{IH}}$ ). The purpose of aggregating over that time horizon is to associate a unit of carbon emissions in a given period with a single measure of damage that reflects the "cost" of that unit of emissions over time, or, conversely, the "benefit" of preventing that unit of emissions in that time period.

There are several variables that affect the path of expected damage from a unit of emissions. One of these is the rate at which atmospheric carbon decays as carbon is re-absorbed into biotic sinks such as forests and oceans, which defines the form and duration of a unit of emissions' residence period in the atmosphere. The way in which this decay is represented varies, with some authors using a fixed decay rate applied to atmospheric stocks (Richards, 1997) and others using an exponential decay function that reflects a declining rate of carbon decay over time (Fearnside, 2000a). In both cases, the decay function reflects the purely physical dynamic of the persistence of carbon in the atmosphere over the impact horizon and translates a unit of emissions into an atmospheric carbon stock impact over time. $^{4}$

The second relationship defining the path of damage expected from a unit of emissions is the relationship between carbon stock and the damage expected from that stock. This relationship translates the physical stock dynamic described by the decay function into a measure of the cost implications of that stock response and moves the "impact horizon" into the realm of economic impact measurement. There are many simplifying assumptions used in different analyses of carbon stock damage over time, including the assumption that marginal damages are not stock-dependent at all or that they are linearly related to stock, but the reality of this relationship is likely more complicated than such assumptions suggest. Recent attempts to represent this relationship in derived estimates of social cost of carbon have relied upon complicated integrated assessment models designed to capture the interactions of multiple underlying variables (Federal Interagency Working Group, 2010).

Each unit of emissions is therefore associated with a path of expected damages over time that reflects both the impact of that unit on atmospheric carbon stocks over time and the 
impact of those carbon stocks on damages from climate change over time. That damage path can then be aggregated over the impact horizon to produce a single social cost of carbon estimate of the expected costs associated with a unit of emissions in a given time period, as denoted by $A$ and $B$ in Figure 1. Because the path of damages is expressed in monetary terms, a discount term is often employed as part of the aggregation to "weight" damages in different time periods according to a judgment about how and whether the value of a dollar of damages changes over time (see Box 1).

Once a path of emission damages has been condensed into a single cost of carbon estimate for units of emissions (or a single benefit number associated with an avoided ton of emissions) in each time period, a second round of aggregating often occurs. In the second round, the purpose of the aggregation is to calculate a single total present value of all the carbon emission costs and avoided emission benefits that occur over the project horizon (denoted $\mathrm{T}_{\mathrm{PH}}$ in Figure 1). This process compares the value of carbon benefit and cost dollars in different time periods, weights them using a discount rate, and then aggregates them to a single number representing total value expressed in present value terms (Figure 1).

The second round of aggregation is a fairly straightforward process of discounting cost and benefit figures over a finite time horizon using economic discounting. The discount factor selected should be internally consistent with the discount factor used to calculate the social cost of carbon in the first round of discounting. Some argue that, in the case of a constant discount rate, the rate should therefore be the same in the two discounting periods (Federal Interagency Working Group, 2010).

\section{Calculation of the social cost of carbon involves a great} deal of uncertainty in the form of uncertain future damage functions, atmospheric carbon stock levels, emissions trajectories, etc. Despite this uncertainty, delays in addressing atmospheric carbon buildup lead to higher levels of risk of catastrophic impacts and damages (Stern, 2007), so climate policy design continues to move forward to address the unfolding impacts of climate change. Many climate

\section{Box 1 | Dollars and Discounting}

Economic analyses generally assume that dollars are not worth the same amount in different time periods. According to this assumption, loss of a dollar in 2050 may not be equivalent, in terms of impact, to loss of a dollar today. If, for instance, it is possible to invest a dollar in an investment vehicle that earns a guaranteed 4 percent interest, then today's dollar will emerge from that investment vehicle in 2050 having grown in value to $\sim \$ 4.80$. In this scenario, a dollar today is more valuable than a dollar in 2050 because there are opportunities to augment the value of today's dollar through market investment. A dollar today is, in a sense, equivalent to $\$ 4.80$ in the future. Similarly, if one invests $\$ 0.21$ in that investment vehicle, it will emerge in 2050 as worth $\sim \$ 1.00$, so a dollar from 2050 is, in a sense, equivalent to $\$ 0.21$ today.

This definition of equivalency (one calculated based on opportunities for market investment) is only one of many that are used to evaluate the changing value of money over time. A great deal of economic literature is dedicated to describing other justifications for assuming that the value of a dollar changes over time, and what the implications of those theories are for definitions of equivalency and selection of an appropriate discount rate.

In all cases, however, converting the value of a dollar in the future to a present value dollar requires advancing some definition of equivalency and using a discount rate that reflects that equivalency to calculate backwards from future values to present values. While there is often consensus that economic decision making should assume some type of changing dollar value over time, there is more disagreement about what underlies that changing value, and often significant disagreement about what discount rate is therefore appropriate.

policies, however, rely on some understanding of the magnitude of the social cost of carbon, and of underlying assumptions about how marginal damages change over time, to ensure that the policies provide the proper incentives or the proper level of control. Establishment of estimates of the SCC, and design of mechanisms for 
dealing with the uncertainty inherent in those numbers, will therefore be a critical element in the development of effective climate policy.

\section{U.S. Interagency Working Group Social Cost of Carbon Estimates}

In 2009, a governmental interagency working group was established and assigned the responsibility of calculating social cost of carbon estimates to be used in benefit/cost analysis of regulations impacting carbon dioxide emissions. The working group relied on three integrated assessment models (the FUND, DICE, and PAGE models) to generate estimates of the monetized damages of climate change impacts associated with carbon dioxide emissions in various time periods. Because such values are extremely sensitive to the discount rate chosen to aggregate impacts over the residence period (or "lifetime") of a unit of carbon in the atmosphere, and because there is so much disagreement about selection of an appropriate discount rate, the working group generated social cost of carbon estimates for three different discounting scenarios: a 2.5 percent, 3 percent, and a 5 percent discount rate. ${ }^{5}$ To illustrate the uncertainty associated with the SCC estimates, the working group also presented a set of SCC estimates that represents the 95 percentile estimates for the 3 percent discount rate scenario. These numbers represent the upper tail of the distribution of impacts, and they are roughly three times the estimates that represent the average of the potential impact distribution (Table 1).

\section{Table 1 | Estimated social cost of carbon figures for} regulatory analysis $\left(\mathbf{S} /\right.$ ton $\left.\mathrm{CO}_{2}\right)$.

\begin{tabular}{|l|c|c|c|c|}
\hline $\begin{array}{l}\text { Emission } \\
\text { Year }\end{array}$ & $\begin{array}{c}\mathbf{5 \%} \\
\text { discount rate } \\
\text { (Average) }\end{array}$ & $\begin{array}{c}\mathbf{3 \%} \\
\text { discount rate } \\
\text { (Average) }\end{array}$ & $\begin{array}{c}\mathbf{2 . 5 \%} \\
\text { discount rate } \\
\text { (Average) }\end{array}$ & $\begin{array}{c}\mathbf{3} \% \\
\text { discount rate } \\
\text { (95 }\end{array}$ \\
\hline 2010 & 4.7 & 21.4 & 35.1 & 64.9 \\
\hline 2015 & 5.7 & 23.8 & 38.4 & 72.8 \\
\hline 2020 & 6.8 & 26.3 & 41.7 & 80.7 \\
\hline 2025 & 8.2 & 29.6 & 45.9 & 90.4 \\
\hline 2030 & 9.7 & 32.8 & 50.0 & 100.0 \\
\hline 2035 & 11.2 & 36.0 & 54.2 & 109.7 \\
\hline 2040 & 12.7 & 39.2 & 58.4 & 119.3 \\
\hline 2045 & 14.2 & 42.1 & 61.7 & 127.8 \\
\hline 2050 & 15.7 & 44.9 & 65.0 & 136.2 \\
\hline
\end{tabular}

The increasing social cost of carbon over time for all the scenarios arises because "future emissions are expected to produce larger incremental damages as physical and economic systems become more stressed in response to greater climate change” (Federal Interagency Working Group, 2010). Note, however, that these values for SCC are expressed in future-year terms; the value of the SCC in 2050 assuming a 3 percent discount rate is projected to be $\$ 44.90 /$ ton of $\mathrm{CO}_{2}$. Expressing those 2050 values in "present value" terms requires discounting them back to the present using an appropriate discount rate. The working group argues that in converting future-year values to present values "damages from future emissions should be discounted at the same rate as that used to calculate the SCC estimates themselves to ensure internal consistency." Applying the respective discount rates to the social costs of carbon estimates assigned to a unit of emissions in each future time period yields the present value of the social cost of carbon estimates shown in Table 2.

\begin{tabular}{|c|c|c|c|c|}
\hline $\begin{array}{l}\text { Emission } \\
\text { Year }\end{array}$ & $\begin{array}{c}5 \% \\
\text { discount rate } \\
\text { (Average) }\end{array}$ & $\begin{array}{c}3 \% \\
\text { discount rate } \\
\text { (Average) }\end{array}$ & $\begin{array}{c}2.5 \% \\
\text { discount rate } \\
\text { (Average) }\end{array}$ & $\begin{array}{c}3 \% \\
\text { discount rate } \\
\text { (95 } 95^{\text {th }} \text { Percentile) }\end{array}$ \\
\hline 2010 & 4.7 & 21.4 & 35.1 & 64.9 \\
\hline 2015 & 4.5 & 20.5 & 33.9 & 62.8 \\
\hline 2020 & 4.2 & 19.6 & 32.6 & 60.0 \\
\hline 2025 & 3.9 & 19.0 & 31.7 & 58.0 \\
\hline 2030 & 3.7 & 18.2 & 30.5 & 55.4 \\
\hline 2035 & 3.3 & 17.2 & 29.2 & 52.4 \\
\hline 2040 & 2.9 & 16.1 & 27.8 & 49.2 \\
\hline 2045 & 2.6 & 15.0 & 26.0 & 45.4 \\
\hline 2050 & 2.2 & 13.8 & 24.2 & 41.8 \\
\hline
\end{tabular}

Note that when expressed in "present value" terms, the value of the SCC is declining over time in all cases. This decline occurs because the rate of growth of the social damage estimates shown in Table 1 (i.e., the rate of increase of the cost to society of carbon emissions over time) is lower than the discount rate used to discount the values back to the present. If the value of damages is growing more slowly than the value of current investments (as reflected in the discount rate used), it is theoretically possible to invest the value of "foregone damages" (at a return equal to the discount rate used) and have it grow 
faster than damages. The result will be an investment that is large enough to compensate for the value of future social damages.

The working group's results can therefore be used to estimate present values for the temporary storage of carbon (foregoing damages early but incurring them later when stored carbon is released). Table 3 shows the estimated per-ton value of storing carbon from 2010 until the release date listed. For example, if a 5 percent discount rate is selected, the value of storing a ton of carbon from 2010 until 2050, and subsequently releasing it, is $\$ 2.47$; in other words, the present value of the costs associated with a ton of carbon released are lowered by $\$ 2.47$ if that unit of emissions is delayed from 2010 until 2050.

Table 3 | Estimated per-ton present value of storing carbon from 2010 until the release date listed $\left(\$ /\right.$ ton $\left.\mathrm{CO}_{2}\right)$.

\begin{tabular}{|l|c|c|c|c|}
\hline $\begin{array}{l}\text { Emission } \\
\text { Year }\end{array}$ & $\begin{array}{c}\mathbf{5 \%} \\
\text { discount rate } \\
\text { (Average) }\end{array}$ & $\begin{array}{c}\mathbf{3 \%} \\
\text { discount rate } \\
\text { (Average) }\end{array}$ & $\begin{array}{c}\mathbf{2 . 5 \%} \\
\text { discount rate } \\
\text { (Average) }\end{array}$ & $\begin{array}{c}\mathbf{3} \% \\
\text { discount rate } \\
\text { (95 }\end{array}$ \\
\hline 2010 & 0.00 & 0.00 & 0.00 & 0.00 \\
\hline 2015 & 0.23 & 0.87 & 1.16 & 2.10 \\
\hline 2020 & 0.53 & 1.83 & 2.52 & 4.85 \\
\hline 2025 & 0.76 & 2.40 & 3.41 & 6.88 \\
\hline 2030 & 1.04 & 3.24 & 4.59 & 9.53 \\
\hline 2035 & 1.39 & 4.21 & 5.87 & 12.51 \\
\hline 2040 & 1.76 & 5.25 & 7.26 & 15.75 \\
\hline 2045 & 2.13 & 6.44 & 9.10 & 19.48 \\
\hline 2050 & 2.47 & 7.64 & 10.89 & 23.15 \\
\hline
\end{tabular}

According to the path of SCC estimates derived by the interagency working group, there is always a positive value to temporary storage of carbon (Table 3). These figures suggest that there are positive benefits to society of storing carbon now, even if it is released later. That value increases with the length of storage and is highly sensitive to the discount rate and structure selected. Also according to these estimates, the value of temporary storage declines as the discount rate increases; the higher the discount rate, the lower the SCC in any time period, because future damages are more heavily discounted. The more heavily the future is discounted, the lower the value that is attached in the present to the damage that future carbon emissions are assumed to cause, and the less value there is to delaying those damages. ${ }^{6}$
The following sections discuss some of the arenas in which the concept of social cost of carbon plays an important role in policy and regulation design in general, as well as the implications for those issues of using the new regulatory social cost of carbon figures as estimates of the temporary value of carbon under different discounting and uncertainty scenarios.

\section{RELEVANT POLICY ARENAS}

The importance of the concept of temporary storage, and how relative values of emissions at different points in time compare, plays out across a number of different policy arenas, including:

- Biofuels greenhouse gas accounting: Accounting for paths of carbon emissions associated with biofuels production in assigning a single greenhouse gas content figure for a gallon of biofuel.

- Reduced emissions from deforestation and forest degradation: Assigning a value to deferred deforestation, where deforestation rates are lowered, but permanent protection is not guaranteed.

- Biological offsets (e.g., in agriculture and forestry): Defining the equivalence of temporary and permanent offsets in order to determine how/whether they should be tradable within the same market.

- Accounting for long-lived versus short-lived forest products in land-use change or product-based accounting: Determining whether/how carbon emission values assigned to long-lived forest products such as timber should differ from shorter-term carbon emissions, such as those arising through burning, in determining the carbon impact of a forestry project.

- Allowance banking and borrowing: Determining an appropriate rate of trade across time for emissions credits that can be banked or borrowed.

The following case studies quantitatively explore the implications of a positive valuation of temporary storage in two contexts: lifecycle GHG accounting for biofuels and agricultural offsets accounting. Some thoughts on implica- 
tions of temporary storage valuation for the debate surrounding deferred emissions from REDD mechanisms are also introduced in Box 4.

\section{CASE STUDY: BIOFUELS, LIFE CYCLE ANALYSIS, AND GREENHOUSE GAS ACCOUNTING}

In the United States and elsewhere, biofuels have been promoted as an alternative to petroleum-based fuels. The anticipated benefits include revitalized rural economies, increased energy independence, and reduced greenhouse gas emissions associated with the transport sector. In recent years, however, experts have raised concerns about the magnitude of greenhouse gas emissions arising from the land-use change associated with the production of biofuel feedstocks. These concerns raise questions about the claims of greenhouse gas benefits associated with biofuel production and use (Searchinger et al., 2008).

The two major regulations supporting biofuels development-California’s "Low Carbon Fuel Standard” and the U.S. Renewable Fuels Standard-therefore require quantification of the greenhouse gas content of the biofuel in order to ensure that it satisfies greenhouse gas requirements attached to the law. In both cases, greenhouse gas "content" is broadly interpreted to mean a life-cycle-based measure of all greenhouse gases emitted throughout the production and transport of the fuel and its major inputs.

The carbon dioxide released when biofuels are combusted as fuel is not included in such accounting because it is "short-cycle" carbon that was absorbed from the atmosphere as the biofuel feedstock grew. However, other GHG emissions arise at several stages in the production of biofuels that must be accounted for, including the GHG emissions associated with clearing or converting land, growing and fertilizing the feedstock, transporting the feedstock, and converting the feedstock into fuel.

Until recently, the potential for significant carbon dioxide emissions associated with land-use conversion for feedstock production was recognized but largely neglected in quantification efforts. Recent research reports, however, have attempted such quantification, arguing that the potential magnitude of these emissions is too significant to ignore (Searchinger et al., 2008). Such emissions are complicated to quantify, however, in part because carbon emissions from land-use change, and the avoided emissions from substituting biofuels for fossil fuels in transport, are ongoing over time and can be difficult to attribute to specific policies. Efforts to quantify the net emissions associated with land-use change and attribute those emissions to current biofuel production or biofuels policy, therefore, must utilize an accounting methodology that allows for aggregation of such emissions into a single figure that can be compared across fuels and across other policy options for reducing GHG emissions. ${ }^{7}$

For such aggregation, it is necessary to select two important analytical parameters: (1) a time frame for analysis that sets temporal boundaries within which emissions or emissions reductions are counted, and (2) some sort of weighting scheme that allows the analyst to compare one unit of emissions (or displaced emissions) that occurs today with a similar unit that occurs at variable points in the future. These parameters are familiar in economic analyses. In cost/benefit analysis they are referred to as the "amortization period" and the "discount rate," and they represent critical policy decisions about the relevant time frame for analysis and how future emissions (or savings) will be valued relative to those today.

In its proposed rule for calculating the greenhouse gas emissions associated with a gallon of biofuel, as required by the Energy Independence and Security Act's Renewable Fuel Standard, the U.S. Environmental Protection Agency proposed two possible methods to handle time in the aggregation of carbon emissions. In the first scenario, carbon costs (i.e., from land use change) and benefits (i.e., from displaced petroleum use) are estimated for 30 years beyond initiation of a biofuel production project. These figures are then aggregated using a 0 percent discount rate to determine net carbon impact over the length of the project. The alternative scenario tracked carbon costs and benefits for 100 years from project initiation and discounted them back to the present for aggregation using a 2 percent discount rate. 


\section{Box 2 I Physical Carbon Discount Rate}

A physical carbon discount rate has been proposed for use in GHG accounting to weight physical units of GHG emissions over time. This rate is used to represent how the "values" of emissions compare across time periods when aggregating emissions into a single carbon impact figure. Suppose an activity or product is going to result in one ton of additional emissions each year for 10 years and the task is to calculate the carbon impact of that product or activity. If it is perceived that units of emissions are equivalent over time, then the carbon impact can be estimated at a 0 percent discount rate (i.e. no change over time) and the total impact is calculated to be 10 tons.

Use of a non-zero physical carbon discount rate, however, reflects a perspective that the importance of emissions in different time periods changes, so that one ton of emissions ten or twenty years from now should not be treated as equivalent to one ton of emissions this year when calculating a total impact figure. A physical carbon discount rate is applied to a unit of emissions to indicate how much weight is attached to that unit of emissions in aggregating emissions over time to arrive at a total impact figure. Use of a $2 \%$ physical carbon discount rate for the GHG accounting problem described above results in the following carbon impact estimate:

\begin{tabular}{|c|c|c|}
\hline \multicolumn{3}{|c|}{$\begin{array}{l}\text { Table } 4 \text { | Use of a physical carbon discount rate to } \\
\text { weight emissions over time in calculating a carbon } \\
\text { impact estimate. }\end{array}$} \\
\hline Year & $\begin{array}{l}\text { Net Yearly } \\
\text { Change }\end{array}$ & $\begin{array}{l}\text { Relative Weight of Emissions with } \\
2 \% \text { Physical Carbon Discount Rate }\end{array}$ \\
\hline 0 & 1 & 1.000 \\
\hline 1 & 1 & 0.980 \\
\hline 2 & 1 & 0.961 \\
\hline 3 & 1 & 0.942 \\
\hline 4 & 1 & 0.924 \\
\hline 5 & 1 & 0.906 \\
\hline 6 & 1 & 0.888 \\
\hline 7 & 1 & 0.871 \\
\hline 8 & 1 & 0.853 \\
\hline 9 & 1 & 0.837 \\
\hline \multicolumn{2}{|c|}{ Total Impact Estimate } & \\
\hline \multicolumn{2}{|c|}{ (Sum of weighted emissions) } & 9.162 \\
\hline
\end{tabular}

The critical question in such an analysis is how to define and measure changing values over time for carbon emissions, and what that definition says about estimating an appropriate physical carbon discount rate.
EPA's proposed rule broke from economic discounting tradition, however, by applying the discount rate directly to physical carbon units rather than to the economic impact of those emissions. Because discount rates are generally used in the context of investment decision making to reflect the "time value of money," they are usually applied to monetary units, such as costs or benefits, rather than to physical units such as tons, million metric tons of carbon equivalent (MMTCE), or pounds (lbs) per acre. Although the practice of applying discount rates directly to physical units to estimate the "time value of carbon" in assessing carbon mitigation options is becoming more common (Stavins and Richards, 2005), a great deal of disagreement exists about the validity of applying discounting principles to carbon units.

The purpose of comparing physical carbon emissions in the future to physical carbon emissions in the present through some sort of discounting procedure is essentially to capture how the value of the damage caused by a unit of emissions in the future will compare to the value of the damage caused by a unit of emissions today (see Box 2). The process of applying a discount rate to carbon tonnage is therefore a "short cut" to information about how the value of damages changes over time that skips the series of important steps described above that translates physical impacts into economic impacts (Marshall, 2009).

When transferring the discounting practice over to physical units, it is important to recognize that, despite a failure to include explicit impact and damage curves in the analysis, the time value of carbon reflected in the discount rate is nevertheless a function of underlying cost and benefit relationships, which are assumed to drive changing "carbon values" over time. In such studies, the discount rate must therefore capture more than just the "time value of money" 
dynamic generally associated with discounting practices. An appropriate physical carbon discount function form and rate must also reflect the complicated relationships described above among variables such as the rate of change of the damages produced by atmospheric GHG stocks (which reflects changing assumptions about available mitigation technologies) and the persistence rate of GHGs in the atmosphere (Richards, 1997). Simple extrapolations from default monetary or market discount rates, or even the lower "social rates of time preference" often used in intergenerational analyses, are generally not appropriate. ${ }^{8}$

\section{Implications of the SCC Estimates for Selection of a Physical Carbon Discount Rate}

The implicit purpose of the discount rate when applied to a physical carbon unit is to reflect the relative weights of the value of damage done by emissions in each time period. The social cost of carbon estimates can therefore be used to derive discount rates which, when applied to the physical carbon unit, produce a discounted physical carbon figure that is proportional to the discounted social cost figure. Such a figure can be used to come up with a discounted carbon content estimate based on "damage-weighted" carbon emissions figures for multiple time periods.

As an example, consider the stream of social cost figures derived in the case of the 2.5 percent discount rate (Table 5). The second column discounts that SCC back to the present year using a 2.5 percent discount figure. The third column then calculates an index of the weight of damages in any given year relative to the damages in year 2010. The objective of a physical discount rate in this context is to generate a path of physical unit weights that equals the path of damage weights relative to the year 2010. If the value of damages created by a unit of emissions in year 2030, for instance, is one-quarter the value of the damages associated with a unit of emissions in year 2010, then the appropriate physical discount rate will be one which, when applied to a single unit of emissions in year 2030, produces a discounted unit weight of 0.25 in the year 2010. The fourth column illustrates the path of appropriate physical carbon discount rates for this particular path of social costs of carbon.
Table 5 | Calculating a physical carbon discount rate from a stream of social cost of carbon values.

\begin{tabular}{|l|c|c|c|c|}
\hline $\begin{array}{c}\text { Emission } \\
\text { year }\end{array}$ & $\begin{array}{c}\text { Scc figure } \\
\text { for } \mathbf{2 . 5 \%} \\
\text { discount rate } \\
\text { scenario }\end{array}$ & $\begin{array}{c}\text { NPV of Scc, } \\
\text { discounted to } \\
\text { present using } \\
\text { a 2.5\% } \\
\text { discount rate }\end{array}$ & $\begin{array}{c}\text { Weight of } \\
\text { damages } \\
\text { relative to } \\
\text { year 2010 }\end{array}$ & $\begin{array}{c}\text { Physical } \\
\text { discount } \\
\text { rate (\%) }\end{array}$ \\
\hline 2010 & 35.1 & 35.1 & 1.000 & 0.000 \\
\hline 2015 & 38.4 & 33.9 & 0.967 & 0.674 \\
\hline 2020 & 41.7 & 32.6 & 0.928 & 0.749 \\
\hline 2025 & 45.9 & 31.7 & 0.903 & 0.683 \\
\hline 2030 & 50.0 & 30.5 & 0.869 & 0.703 \\
\hline 2035 & 54.2 & 29.2 & 0.833 & 0.734 \\
\hline 2040 & 58.4 & 27.8 & 0.793 & 0.775 \\
\hline 2045 & 61.7 & 26.0 & 0.741 & 0.861 \\
\hline 2050 & 65.0 & 24.2 & 0.690 & 0.933 \\
\hline
\end{tabular}

Note that the appropriate physical discount rate (shown in column five) is significantly lower than the economic discount rate used in the analysis (which in this case is 2.5 percent). Furthermore, the schedule of physical discount rates to be applied to emissions in the different years is non-constant and increasing over time. This dynamic arises because the estimated SCC figures increase at a declining rate over time.

To illustrate how such discounting figures might be applied in the context of GHG accounting for biofuels production, consider the problem of calculating the GHG impact associated with the production of ethanol from an acre of land. A very stylized schedule of production emissions might appear as shown in Table 6. These figures reflect large up-front costs associated with potential carbon emissions from land-use change, followed by a stream of benefits associated with displaced petroleum use from ethanol produced on the land for 30 years after conversion.

According to EPA's finalized rules for the calculation of GHG impacts under the Renewable Fuels Standard, such emissions should be aggregated over 30 years using a discount rate of 0 percent. The calculations shown in Table 5 suggest that, even with a project period of 30 years, a non-zero discount rate is appropriate if the objective of the aggregation is to generate a "damage-weighted" total of emissions costs and benefits over time. The results in Table 
Table 6 | Using a physical carbon discount rate, derived from the social cost of carbon, to weight carbon units over time (using estimates derived with a 2.5 percent discount rate).

\begin{tabular}{|c|c|c|c|c|c|}
\hline Year & $\begin{array}{l}\text { Costs: emissions } \\
\left(\mathrm{TCO}_{2} \mathrm{e}\right)\end{array}$ & $\begin{array}{c}\text { Benefits: avoided } \\
\text { emissions from } \\
\text { petroleum use }\left(\mathrm{TCO}_{2} \mathrm{e}\right)\end{array}$ & $\begin{array}{l}\text { Schedule of } \\
\text { physical carbon } \\
\text { discount rates }\end{array}$ & $\begin{array}{l}\text { Discounted costs } \\
\left(\mathrm{TCO}_{2} \mathrm{e}\right)\end{array}$ & $\begin{array}{l}\text { Discounted benefits } \\
\left(\mathrm{TCO}_{2} \mathrm{e}\right)\end{array}$ \\
\hline 2010 & 20.0 & 0.0 & 0.000 & 20.000 & 0.000 \\
\hline 2011 & 5.0 & 2.0 & 0.777 & 4.961 & 1.985 \\
\hline 2012 & 4.0 & 2.0 & 0.653 & 3.948 & 1.974 \\
\hline 2013 & 3.0 & 2.0 & 0.715 & 2.937 & 1.958 \\
\hline 2014 & 2.0 & 2.0 & 0.685 & 1.946 & 1.946 \\
\hline 2015 & 1.0 & 2.0 & 0.674 & 0.967 & 1.934 \\
\hline 2016 & 0.1 & 2.0 & 0.716 & 0.096 & 1.916 \\
\hline 2017 & 0.1 & 2.0 & 0.713 & 0.095 & 1.903 \\
\hline 2018 & 0.1 & 2.0 & 0.714 & 0.094 & 1.889 \\
\hline 2019 & 0.1 & 2.0 & 0.746 & 0.094 & 1.871 \\
\hline 2020 & 0.1 & 2.0 & 0.749 & 0.093 & 1.856 \\
\hline 2021 & 0.1 & 2.0 & 0.733 & 0.092 & 1.846 \\
\hline 2022 & 0.1 & 2.0 & 0.703 & 0.092 & 1.839 \\
\hline 2023 & 0.1 & 2.0 & 0.698 & 0.091 & 1.827 \\
\hline 2024 & 0.1 & 2.0 & 0.697 & 0.091 & 1.815 \\
\hline 2025 & 0.1 & 2.0 & 0.683 & 0.090 & 1.806 \\
\hline 2026 & 0.1 & 2.0 & 0.687 & 0.090 & 1.792 \\
\hline 2027 & 0.1 & 2.0 & 0.692 & 0.089 & 1.779 \\
\hline 2028 & 0.1 & 2.0 & 0.687 & 0.088 & 1.768 \\
\hline 2029 & 0.1 & 2.0 & 0.694 & 0.088 & 1.754 \\
\hline 2030 & 0.1 & 2.0 & 0.703 & 0.087 & 1.739 \\
\hline Total & 36.5 & 40 & & 36.129 & 37.196 \\
\hline \multicolumn{2}{|l|}{ Net benefits } & 3.5 & & & 1.066 \\
\hline
\end{tabular}

6 illustrate that the use of this discount schedule discounts the stream of future benefits sufficiently to narrow the gap between project benefits and costs (from a net benefit of 3.5 in the undiscounted case to just 1.1 in the discounted case). As one might expect, use of a physical discount rate could tip the comparison so that costs exceed benefits if the physical emissions and savings figures are sufficiently close in the un-discounted case. Table 7 illustrates a case where a project with net benefits of 1.5 in the un-discounted case becomes undesirable, with a net benefit of -0.8 , in the discounted case.

In this analysis, the discounted case accounts for the fact that there is a foregone storage benefit associated with the release of large amounts of carbon at the front end of the project through land-use change. Use of the discount rate therefore narrows the margins of benefits for the project relative to the case where the value of temporary storage is not accounted for.

\section{CASE STUDY: BIOLOGICAL OFFSETS AND TEMPORARY CARBON STORAGE VALUE}

As potential designs for climate legislation are debated in the United States, one central area of discussion has been about the extent to which the agricultural and forestry sectors can or should be involved as a source of offset credits for capped sectors under a climate bill. Offset credits represent reductions in an uncapped sector that can be sold into a capped sector and substituted for required reductions. Proponents argue that there are many sources of "low hanging fruit" within agriculture and forestry where sequestration could occur at relatively low cost and that such reductions would help keep the costs of compli- 
Table 7 | Example of a scenario where the project is desirable when carbon is not discounted, but where costs exceed benefits when carbon is discounted using a physical carbon discount rate based on the SCC (using estimates derived with a $\mathbf{2 . 5}$ percent discount rate).

\begin{tabular}{|c|c|c|c|c|c|}
\hline & $\begin{array}{l}\text { Costs: emissions } \\
\left(\mathrm{TCO}_{2} \mathrm{e}\right)\end{array}$ & $\begin{array}{l}\text { Benefits: avoided } \\
\text { emissions from } \\
\text { petroleum use }\left(\mathrm{TCO}_{2} \mathrm{e}\right)\end{array}$ & $\begin{array}{l}\text { Schedule of } \\
\text { physical carbon } \\
\text { discount rates }\end{array}$ & $\begin{array}{l}\text { Discounted costs } \\
\left(\mathrm{TCO}_{2} \mathrm{e}\right)\end{array}$ & $\begin{array}{l}\text { Discounted benefits } \\
\left(\mathrm{TCO}_{2} \mathrm{e}\right)\end{array}$ \\
\hline 2010 & 20.0 & 0.0 & 0.000 & 20.000 & 0.000 \\
\hline 2011 & 5.0 & 1.9 & 0.777 & 4.961 & 1.885 \\
\hline 2012 & 4.0 & 1.9 & 0.653 & 3.948 & 1.875 \\
\hline 2013 & 3.0 & 1.9 & 0.715 & 2.937 & 1.860 \\
\hline 2014 & 2.0 & 1.9 & 0.685 & 1.946 & 1.849 \\
\hline 2015 & 1.0 & 1.9 & 0.674 & 0.967 & 1.837 \\
\hline 2016 & 0.1 & 1.9 & 0.716 & 0.096 & 1.820 \\
\hline 2017 & 0.1 & 1.9 & 0.713 & 0.095 & 1.808 \\
\hline 2018 & 0.1 & 1.9 & 0.714 & 0.094 & 1.795 \\
\hline 2019 & 0.1 & 1.9 & 0.746 & 0.094 & 1.777 \\
\hline 2020 & 0.1 & 1.9 & 0.749 & 0.093 & 1.763 \\
\hline 2021 & 0.1 & 1.9 & 0.733 & 0.092 & 1.753 \\
\hline 2022 & 0.1 & 1.9 & 0.703 & 0.092 & 1.747 \\
\hline 2023 & 0.1 & 1.9 & 0.698 & 0.091 & 1.736 \\
\hline 2024 & 0.1 & 1.9 & 0.697 & 0.091 & 1.724 \\
\hline 2025 & 0.1 & 1.9 & 0.683 & 0.090 & 1.716 \\
\hline 2026 & 0.1 & 1.9 & 0.687 & 0.090 & 1.703 \\
\hline 2027 & 0.1 & 1.9 & 0.692 & 0.089 & 1.690 \\
\hline 2028 & 0.1 & 1.9 & 0.687 & 0.088 & 1.680 \\
\hline 2029 & 0.1 & 1.9 & 0.694 & 0.088 & 1.666 \\
\hline 2030 & 0.1 & 1.9 & 0.703 & 0.087 & 1.652 \\
\hline Total & 36.5 & 38 & & 36.129 & 35.336 \\
\hline \multicolumn{2}{|l|}{ Net benefits } & 1.5 & & & -0.794 \\
\hline
\end{tabular}

ance with climate legislation low within the capped sector while providing additional income opportunities for the agricultural and forestry sectors. Some policymakers are particularly enthusiastic about the potential for sequestering carbon in terrestrial ecosystems through an increase in biomass or soil organic carbon (van Kooten, 2008).

Such offset opportunities, termed "biological" or "sequestration" offsets, differ fundamentally from other potential offset opportunities within agriculture, however. Offsets generated from the use of methane digesters, changes in fertilizer use, and other agricultural practices represent emissions reductions that are permanent; future changes in practices will not re-emit the carbon reductions achieved through use of the technology or practice. Biological sequestration projects can make no such guarantee. Forests grown this year for sequestration purposes, for instance, could be harvested in 30 years if timber market prices change or could accidentally burn and release stored carbon as a result of natural processes. Because biological sequestration cannot guarantee permanent storage, it is difficult to define how such biological offsets "stack up" against permanent reductions in meeting emissions reductions goals for climate policy. Defining some measure of equivalence between permanent reductions and biological offsets, however, is critical to designing offset markets that allow one to be traded for the other.

The "permanence" issue in the biological offsets debate addresses the question of how policy can be designed to ensure that activities that are inherently impermanent can 
generate offset credits that are considered equivalent, by some definition, to permanent reductions. Proposed institutional design solutions to this problem have included: permanent enforcement, continuous liability rules, credit discounting, ton-year accounting, minimum period for project lifetime, temporary "Certified Emissions Reductions” (CERs), buffers for risk management, and annually rented credits of some kind (Blanco and Forner, 2000; Fearnside, 2008; Sedjo and Marland, 2003; Bigsby, 2009).

There are two different approaches to the design of solutions to permanence issues with respect to biological offsets. One approach considers temporary offsets to be simply an interim storage mechanism that is just one part of a permanent sequestration path. According to this approach, the challenge to solving the permanence problem is ensuring that when and if the biological offset project "reverses" and re-emits its stored carbon, the purchaser of the temporary credit takes measures to ensure re-sequestration through either another temporary credit or a permanent reduction elsewhere. Sedjo and Marland (2003) reflect this approach in describing the problem of permanence in the offsets markets as a liability issue. The question is not whether carbon can be stored indefinitely using a particular technology or practice, but whether liability can be maintained indefinitely so that reversals must be compensated for and the stream of sequestration maintained intact, though the form of that sequestration may vary with time.

Institutional solutions such as annually rented credits and permanent liability rules approach the problem from this perspective. The underlying theory is straightforward: permanent liability leads to permanent sequestration. A regulated party can meet its compliance obligation by renting annual credits, but eventually will have to satisfy that liability by investing in permanent reductions within its facilities or through the purchase of an emissions allowance or another temporary offset credit. In practice, however, ensuring that liability will extend indefinitely into the future is extremely complex. Companies go out of business, regulations change, and enforcement resources are limited. Additional institutional refinements attempt to deal with these risks through mechanisms such as credit buffer reserves and compliance obligations under climate policy to insure against future losses. Nevertheless, the fundamental premise of this approachthat if companies are allowed to hold temporary credits some mechanism needs to be in place to monitor them, possibly indefinitely, to ensure those temporary credits eventually become permanent-may be untenable, and, if you subscribe to the second approach to temporary credit design, unnecessary.

The second, alternative approach to temporary credits argues that it should be possible to define some measure of “equivalence” between temporary credits and permanent reductions that can be used to determine how temporary credits of different lengths of time compare in effectiveness to permanent reductions. Equivalence could be defined by a specified duration period, for instance, so that any offset generated by a storage project that lasts 50 years is equivalent to a permanent reduction today. Ton-year accounting is a commonly used accounting method that relies upon a determination of equivalence duration such as this (see Box 3).

The relative values derived from the ton-year method, however, are highly sensitive to the equivalence duration chosen; the longer the equivalence duration, the less value is awarded to temporary storage. There is a great deal of debate about whether a 100-year assumption is appropriate or arbitrary, but it has the advantage of being consistent with the construction of the Global Warming Potential indices that are used to determine equivalence among the impacts of different greenhouse gasses in the atmosphere (Herzog et al., 2003).

\section{Implications of Social Cost of Carbon Estimates for Equivalence Estimates}

Like discounting physical carbon in the context of biofuel GHG accounting, the equivalence concept introduced here, though often measured in physical units such as ton-years, can be interpreted as a shortcut for comparing the value of damages done by emissions in different time periods. In the context of temporary credits, a permanent reduction can be said to be equivalent to the number of temporary 


\section{Box 3 | Ton-Year Accounting}

The ton-year accounting method is one method often proposed as a way to compare the value of temporary storage to a permanent reduction or to other storage projects of different durations. This method relies on an underlying duration equivalence assumption, often 100 years, that essentially asserts that storage of 100 years or longer is considered permanent and therefore equivalent to a permanent reduction (Herzog et al., 2003; Fearnside, 2002a). Storage of less than 100 years is discounted. Herzog et al. (2003) explain “the 'discount' for non-permanent storage is based on differences in the integrated atmospheric carbon over the 100 years from a pulse of carbon removed from the atmosphere at time $t=0$ and re-emitted to the atmosphere at time $\mathrm{t}=\mathrm{T}$ based on a simulation of a carbon cycle model" (Figure 2).

Note that due to degradation in the atmosphere, a permanent reduction is considered equivalent to 46 ton-years, given a 100-year frame of consideration. In contrast, a ton of carbon stored in a forestry project and released in year 50 has a ton-year benefit equal to the difference between emitting the unit now (46 ton-years) and emitting the unit in year 50 (28 ton-years), or 18 ton-years. Such a project would therefore be credited with 18 ton-years of storage, versus a permanent reduction that is credited with 46 ton-years of storage.
Figure 2 The impact of a unit of emissions in year $\mathbf{O}$ (as measured in ton-years and shown in Panel A) is compared to the impact of a unit of emissions in year $\mathbf{5 0}$ (Panel B; Fearnside et al., 2000).

A

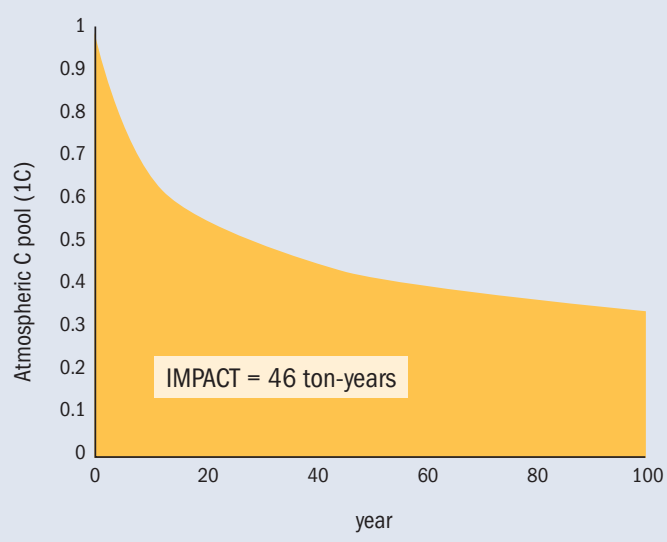

B

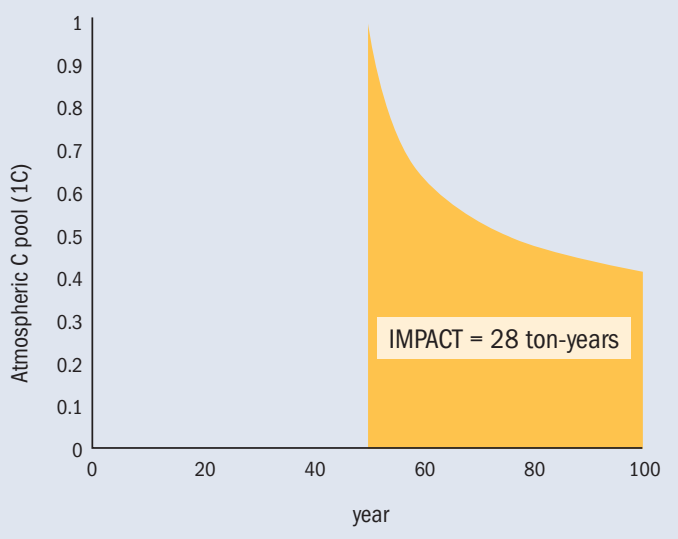

reductions that provide an equivalent level of damage reduction. Theoretically, if used as a trading ratio between permanent and temporary credits, that ratio should create an equivalence relationship that yields a comparable impact between permanent reduction and the requisite number of temporary credits, and ensures that the respective market prices reflect the relative impacts of temporary versus permanent storage.

As an example, consider the 5 percent discount rate scenario shown in Table 1 (which illustrates the net present value [NPV] figures for the social cost of carbon estimates). Those estimates suggest that a ton of carbon dioxide emitted in 2010 generates $\$ 4.70$ worth of dam- ages. Determining an appropriate trading ratio with temporary credits would require calculating, for each potential project duration, the number of temporary credits required for the NPV of the avoided damages from those temporary credits to be equivalent to $\$ 4.70$ per ton of carbon dioxide. Consider that a ton of carbon dioxide emitted in 2050 is estimated to generate \$2.23 worth of damage. The value of sequestering that ton, in terms of avoided damages, from 2010 to 2050 is therefore $\$ 4.70$ $\$ 2.23=\$ 2.47$ (Table 3). When using a 5 percent discount rate, a permanent reduction of one ton of carbon in 2010 is therefore equivalent to $4.70 / 2.47=1.9$ tons of 40 -year storage, or permanently reducing a unit of carbon in 2010 is equivalent, in terms of the value of damages avoided, 
to temporarily storing 1.9 units of carbon dioxide from 2010 to 2050.

As one would expect, the equivalence ratios for shorter projects are much higher than they are for longer projects. In the case of ten-year storage credits, for instance, the benefit of the storage is only $\$ 4.70$ - $\$ 4.17=\$ 0.53$ per ton of carbon sequestered. One would therefore need to purchase 9.0 (4.7 / 0.53) temporary, ten-year storage credits in order to avoid the same amount of damage as permanent reduction avoids. The equivalence trading ratios calculated for each discounting scenario are shown in 8.

\section{Table 8 Equivalence trading ratios for temporary credits of different durations and under different discounting scenarios.}

\begin{tabular}{|c|c|c|c|}
\hline $\begin{array}{l}\text { Year of temporary } \\
\text { credit expiration }\end{array}$ & $\begin{array}{l}5 \% \text { discount } \\
\text { rate (Average) }\end{array}$ & $\begin{array}{l}3 \% \text { discount } \\
\text { rate (Average) }\end{array}$ & $\begin{array}{l}2.5 \% \text { discount } \\
\text { rate (Average) }\end{array}$ \\
\hline 2010 & $\mathrm{~N} / \mathrm{A}$ & $\mathrm{N} / \mathrm{A}$ & $\mathrm{N} / \mathrm{A}$ \\
\hline 2015 & 20.10 & 24.60 & 30.30 \\
\hline 2020 & 8.95 & 11.70 & 13.91 \\
\hline 2025 & 6.22 & 8.91 & 10.30 \\
\hline 2030 & 4.50 & 6.61 & 7.65 \\
\hline 2035 & 3.37 & 5.09 & 5.98 \\
\hline 2040 & 2.67 & 4.08 & 4.84 \\
\hline 2045 & 2.21 & 3.32 & 3.86 \\
\hline 2050 & 1.90 & 2.80 & 3.22 \\
\hline
\end{tabular}

These estimates suggest that as the discount rate used decreases, the necessary trading ratio between temporary credits and permanent reductions increases. This is because as the discount rate decreases, damages from future emissions are discounted less. If future emissions have higher relative damages, then the value of temporary storage goes down, as does the value of temporary storage credits relative to permanent reductions (see note 6).

\section{UNCERTAINTY AND THE VALUE OF TEMPORARY CARBON STORAGE}

Thus far, average values have been used to illustrate the value of temporary carbon storage derived from the interagency working group social cost of carbon numbers. It is important to consider, however, that the social cost of carbon estimation effort produces a full range, or distribu- tion, of potential impacts and costs, from which is derived a single average cost estimate. Averages are one method used to "represent" a full distribution of results; they have the advantage of being commonly used and easily understood as one method of representing the "center” of a distribution. Averages are so common, in fact, that representing a distribution of potential estimates through the use of an average (or a median-another measure of the “center" of a distribution) is often taken for granted as being appropriate across policy contexts.

In fact, use of the average to represent a distribution of results is a policy decision that reflects an underlying attitude toward the uncertainty associated with the distribution of outcomes. Consider that using the time path of average damages for a given discounting scenario to represent future costs means that, even if you accept the range of modeled outcomes as a reasonable range of outcomes, there is a 50 percent probability that social costs of carbon in any time period exceed the costs that have been selected as representative for regulatory purposes. There is also, of course, a 50 percent probability that social costs of carbon in any time period are lower than those costs. While risk is symmetric, however, theories of risk aversion have consistently demonstrated that individuals' perception of risk may not be symmetric; individuals often perceive the risks of increased costs (the down-side risk) differently than they perceive the up-side risks, or the possibility that costs will not be as high as the expected cost reflected in the average. "Risk aversion” refers to a willingness to pay to avoid down-side risk; in the case of policy design based on a social cost of carbon, a policy reflecting a greater degree of risk aversion might choose a social cost of carbon value in the upper tail of the cost distribution as the basis of its policy design in order to reduce the down-side risk associated with the policy outcome.

Anda et al. (2009) argue that there are other reasons that conventional expected values, or averages, may not be the appropriate figure upon which to base policy design in the case of projected climate change outcomes: "the conventional approach does not account for the presence of thresholds in the concentration-response function and the risk of global catastrophic climate events that, though 


\section{Box 4 | Temporary Storage and the REDD Debate}

The combined effects of deforestation, forest degradation, and peatland emissions are estimated to generate 8-20 percent of global anthropogenic greenhouse gas emissions (van der Werf et al., 2009). Actions to reduce deforestation will therefore be an important part of any strategy to avoid catastrophic climate change. Reducing Emissions from Deforestation and Forest Degradation (REDD) is a proposed framework under the United Nations Framework Convention on Climate Change (UNFCCC) to encourage developing countries to reduce forest-related emissions. One element of the REDD framework will likely include providing a financial incentive for emissions reductions that occur as a result of actions taken to slow rates of deforestation and forest degradation.

One of the debates in the international negotiations on REDD is whether the emissions reductions generated through such actions could be used by countries with emissions reductions targets to meet their obligations under an international climate change agreement. Under such a system, developed countries could offset part of their emission reduction obligations by buying emissions reductions generated by REDD actions in tropical forest countries. While such a mechanism could be structured so that payments are negotiated and transferred at the project level, like a large international offset program, current discussions are focused on having the system operate at the national level, where countries themselves generate tradable carbon credits in exchange for lowering their national deforestation rate below a defined baseline level.
Much of the debate surrounding the legitimacy of the GHG reductions achievable through a REDD mechanism raises questions related to the permanence of reductions achieved through changes in forest management. The permanence issue arises because, like all other biological sequestration methods, changes in forest management result in sequestration that can ultimately be reversed, either naturally through wildfire, for instance, or through anthropogenic land use change. The incentives provided by a REDD mechanism may therefore defer, but perhaps not ultimately avoid, deforestation and release of stored carbon.

Another active area of discussion is the potential for "leakage" of emissions associated with changing patterns of land use arising as a result of GHG mitigation projects.

"Leakage" refers to the possibility that increased protection of forests in one area will lead to increased pressure on, and increased deforestation of, forests in another area. With high levels of leakage, carbon credits generated by the initial forest protection program could overestimate actual aggregate reductions in emissions; a portion of the emissions counted as reduced have in fact shifted geographically. While permanence is concerned with the extent to which emissions are avoided versus simply displaced in time, leakage is concerned with the extent to which emissions are avoided versus simply displaced in space.

In the case of a project-level REDD mechanism, the implications of the SCC figures for the negotiated contracts between forest owners and international buyers are the same as those described in the section on biological offsets; a trading ratio between the impermanent carbon characterized by a low probability of occurrence, would lead to significant economic damage.” This argument builds on the work of Tol (2003) and Weitzman (2007) in making the case that averaging climate outcomes may not be an appropriate tool when analyzing irreversible processes with "heavy-tailed" distributions_or distributions with a large amount of weight in one tail rather than in the center. They suggest that under circumstances where the risk of irreversible climate catastrophe creates a heavy upper tail in the distribution of potential climate change costs, climate policy should be designed to "hedge against the risk that greenhouse gas emissions will lead to catastrophe” (Anda et al., 2009).

In the presence of irreversibility, hedging against future catastrophic risk entails recognizing the additional value associated with keeping policy options open and maintaining the flexibility to adjust policies in response to new 
credits from sequestration and the credits obtained from permanent reductions or avoided emissions can capture the relative difference in magnitude of damages avoided. .i The length of the contract agreed upon will determine the appropriate trading ratio. Note that a trading ratio as described addresses the permanence issue through its proposed definition of equivalence, but it does not address the issue of leakage.

A REDD mechanism operating at the national level, on the other hand, addresses within-country emissions leakage risk by generating credits based on the performance of the entire country, rather than on a project-by-project basis. A country's performance would be measured relative to a national established baseline for deforestation rates; the methodology for determining national baselines that seems to be generating the most discussion is one based on a multi-year average of historical deforestation rates.ii As in the case of the project-level REDD mechanism, trading ratios could be used at the national level to ensure some level of equivalence between the deferred carbon release purchased from developing countries through the REDD offset mechanism and the permanent reductions that are foregone in developed countries.

The use of a trading ratio absolves developing countries of the liability to replace temporary credits when they expire by ensuring that multiple temporary storage credits offset an equivalent amount of damage to permanent reductions. ${ }^{\text {iv }}$ Awarding value to fixed-length contracts, while at the same time recognizing them as fixed-length and therefore of variable carbon-mitigation value depending on the length of the storage period, may help find middle ground between source country concerns about national sovereignty over natural resources and environmental concern about the integrity of the credits sold.

\section{Notes}

i. Ebeling and Yasue (2008) argue that reducing deforestation rates is as "permanent" as fossil fuel-use reductions, which still leave the fuel in the ground for possible later use. If all fossil fuels are ultimately going to be exploited, then any current reduction measure is actually a deferral of use. They argue that the value of such reductions lies in how they impact the timing of emissions: "In fact, a time delay in emissions through temporary abatement measures results in permanent climate benefits because the cumulative atmospheric concentrations of GHGs will be lower at any future point in time." Note the distinction between permanent sequestration and permanent benefits; the argument is that non-permanent sequestration can still provide permanent benefits. The value of temporary storage of carbon reflects those permanent benefits.

ii. Under project-level mechanisms the baseline against which emissions removals are measured over time is the estimated amount of emissions that would have been expected under a "business-as-usual scenario." Put another way, these are the emissions expected in the absence of the project activity (in this case, avoiding deforestation).

iii. There are objections to establishing a baseline this way, largely based on the fact that deforestation patterns do not tend to stay constant over a country's history, even in a "business-as-usual" situation. Observed "forest transitions" at the national level suggest that a dynamic baseline should reflect decreasing deforestation rates over time and with development. The myriad difficulties associated with selecting a baseline are not the topic of this paper, however.

iv. This structure is in contrast to the temporary credits generated by land use, land-use change, and forestry (LULUCF) activities under the E.U. Emission Trading Scheme. Under the LULUCF structure, governments assume liability to replace or renew temporary LULUCF credits once they expire; offset credits used in conjunction with ongoing liability for permanent reduction represent interim carbon storage mechanisms rather than the temporary storage mechanisms described in this paper. knowledge that narrows uncertainty in the future (Anda et al., 2009). An approach to climate policy that recognizes the importance of option value may conclude that it is appropriate to adopt additional policy costs in order to maintain policy flexibility; in the context of policy designs based on social cost of carbon estimates, decision makers may again decide to use social cost of carbon estimates in the upper tail of the distribution, rather than at the center, as one method of hedging against the risk of catastrophic collapse in the future. ${ }^{9}$

In either case, the task of calculating the appropriate expenditure as a risk premium or hedge against catastrophic change is well beyond the scope of this analysis. However, the working group presented a set of upper-tail social cost of carbon estimates that can be used to illustrate the implications in different policy contexts of using more 
conservative, upper-tail estimates of social cost of carbon than the average figures used earlier. In the case of a 3 percent discount rate, the working group presents both the average and the $95^{\text {th }}$ percentile estimate. The $95^{\text {th }}$ percentile estimate represents the SCC level that separates the lower 95 percent of the distribution of possible SCC outcomes from the upper 5 percent. By definition, this figure is substantially higher than the average social cost of carbon in every time period; less intuitively, in this particular case, the spread of the social cost of carbon distribution increases at the same rate as the mean, so that the ratio of the $95^{\text {th }}$ percentile to the arithmetic mean remains roughly constant (Table 9).

Table 9 | Estimates at different points in the outcome distribution for the $\mathbf{3}$ percent discount rate scenario.

\begin{tabular}{|l|c|c|c|}
\hline Year & $\begin{array}{c}\text { 3\% discount } \\
\text { rate } \\
\text { (Average) }\end{array}$ & $\begin{array}{c}\text { 3\% discount rate } \\
\text { (95th percentile) }\end{array}$ & $\begin{array}{c}\text { 3\% discount rate } \\
\text { (Ratio of 95th to } \\
\text { Average) }\end{array}$ \\
\hline 2010 & 21.4 & 64.9 & 3.0 \\
\hline 2015 & 23.8 & 72.8 & 3.1 \\
\hline 2020 & 26.3 & 80.7 & 3.1 \\
\hline 2025 & 29.6 & 90.4 & 3.1 \\
\hline 2030 & 32.8 & 100.0 & 3.0 \\
\hline 2035 & 36.0 & 109.7 & 3.0 \\
\hline 2040 & 39.2 & 119.3 & 3.0 \\
\hline 2045 & 42.1 & 127.8 & 3.0 \\
\hline 2050 & 44.9 & 136.2 & 3.0 \\
\hline
\end{tabular}

The roughly constant relationship between the $95^{\text {th }}$ percentile and the mean has significant implications for the use of the $95^{\text {th }}$ percentile rather than the mean in both the biofuels and the agricultural offsets cast studies. Calculation of both the SCC-equivalent physical carbon discount rate and a permanence equivalence ratio for temporary offset credits depends on ratios calculated from the path of social cost of carbon values over time. If the path of the $95^{\text {th }}$ percentile estimates over time is an exact multiple of the path of average estimates over time, then the multiplier cancels out in calculating the relevant ratios along the $95^{\text {th }}$ percentile path, and the ratios used to calculate the physical carbon discount rate and the appropriate offset trading ratio are exactly the same as those calculated using the average path. In other words, carbon storage values are derived from relative cost of carbon estimates over time, not from the absolute estimates themselves. Therefore, if the absolute social cost of carbon estimates found at different certainty levels along the outcome distribution all increase at the same rate over time, there will be no difference in the temporary storage values calculated using different levels of certainty.

The current social cost of carbon estimates come very close to replicating that scenario, though one can see from Table 8 that the $95^{\text {th }}$ percentile estimates diverge slightly from a fixed ratio for the years 2015-2025. Although the modest divergence present in the existing estimates is likely a modeling artifact, and there is not enough information in the SCC documentation to attribute the divergence to specific input structures or assumptions, it is nevertheless instructive to explore the implications of the divergence in the different policy contexts described here. In future studies, increased focus specifically on how the distribution of potential cost estimates changes over time will help clarify the relationship between uncertainty of input parameters, uncertainty of outputs, and the implications for policy based on a temporary storage value analysis.

In the context of physical carbon discounting, the fact that the $95^{\text {th }}$ percentile estimates are slightly higher than proportional over a portion of the path reflects that the SCC values do not decline as quickly early in the time horizon, then decline faster in later years in order to become proportional again (Figure 3). The ratio of damages relative to year 1 is therefore higher in the early years for the $95^{\text {th }}$ percentile (Figure 4). The result is a slightly lower damageequivalent physical carbon discount rate for emissions occurring early in the time horizon when the $95^{\text {th }}$ percentile estimates are used.

In the context of calculating trading ratios for agricultural offsets, the fact that the $95^{\text {th }}$ percentile SCC estimates stay proportionately higher early in the time horizon means that the value of temporary credits that expire in those time periods is relatively lower in the case of the $95^{\text {th }}$ percentile than in the average case. Therefore, for those time periods in which higher than proportional estimates are maintained, more temporary credits will be required in order to reach equivalence with the benefits achieved through a perma- 


\section{Figure 3 I SCC estimates at the 95th percentile versus a fixed multiple of the average estimates.}

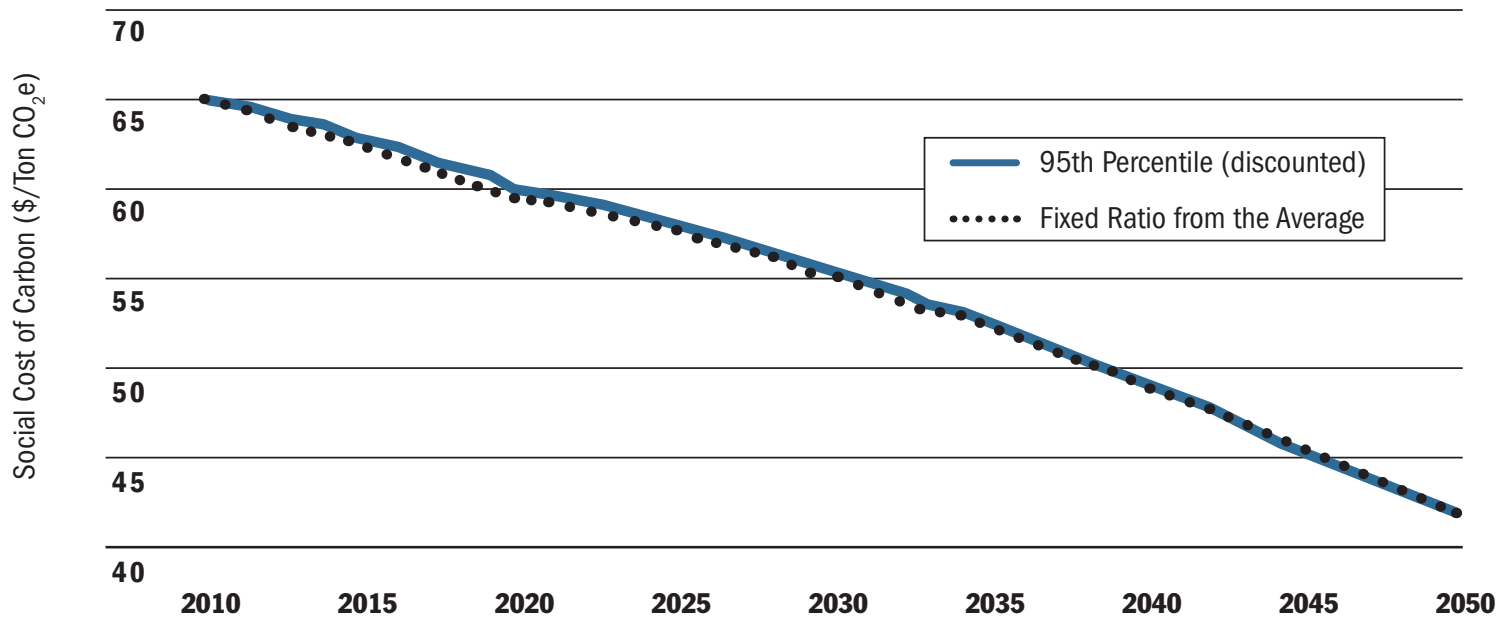

Figure 4 | SCC Ratio of discounted damages from emissions in any year relative to those in year $\mathbf{1}(2010)$ and the resulting damage-equivalent physical carbon discount rate.

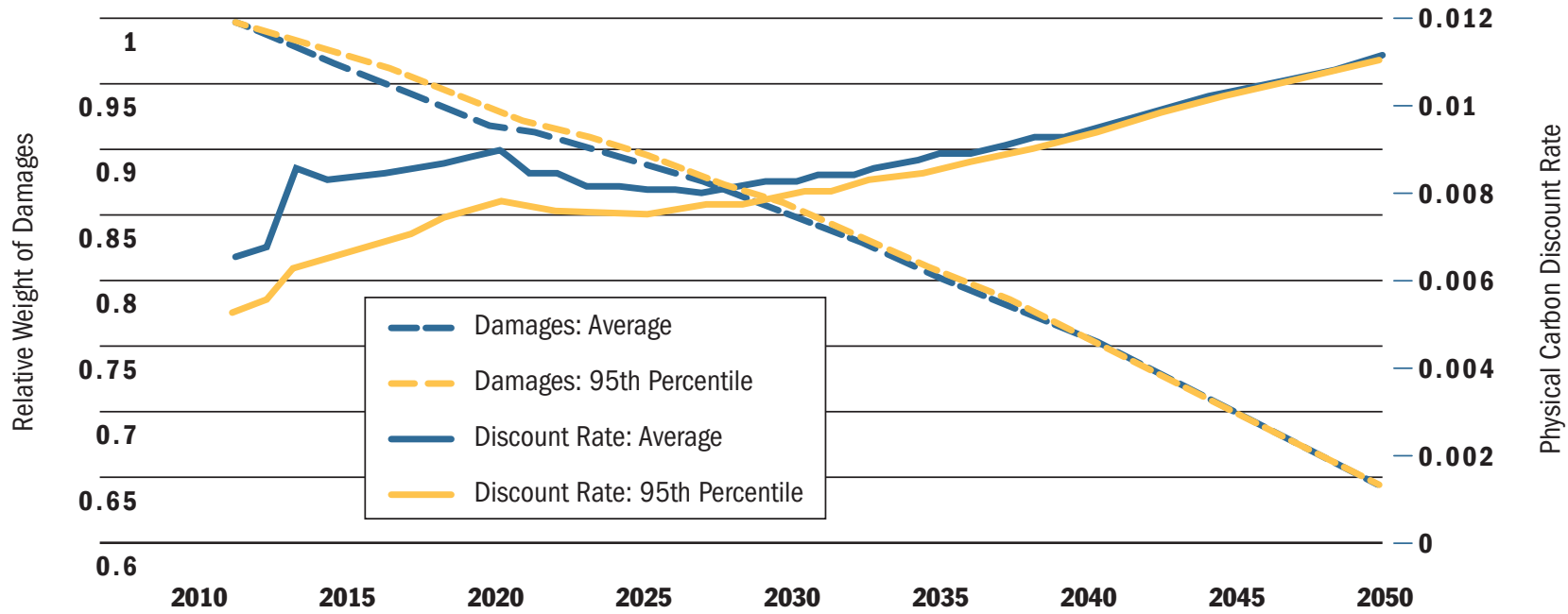

nent reduction than are required in the average estimates case (Figure 5).

It is important to reiterate that the results illustrated here derive from the fact that the $95^{\text {th }}$ percentile estimates stay close to a fixed multiple of the average estimates. These results highlight that the critical element in an examination of the relative value of the temporary storage of carbon is the ratio of SCC costs at some point in the future to the current costs; even though absolute SCC costs along the $95^{\text {th }}$ percentile are much higher than those along the average, the value of temporary storage relative to a permanent reduction is similar along the two paths because they are close to fixed multiples of each other. Future 


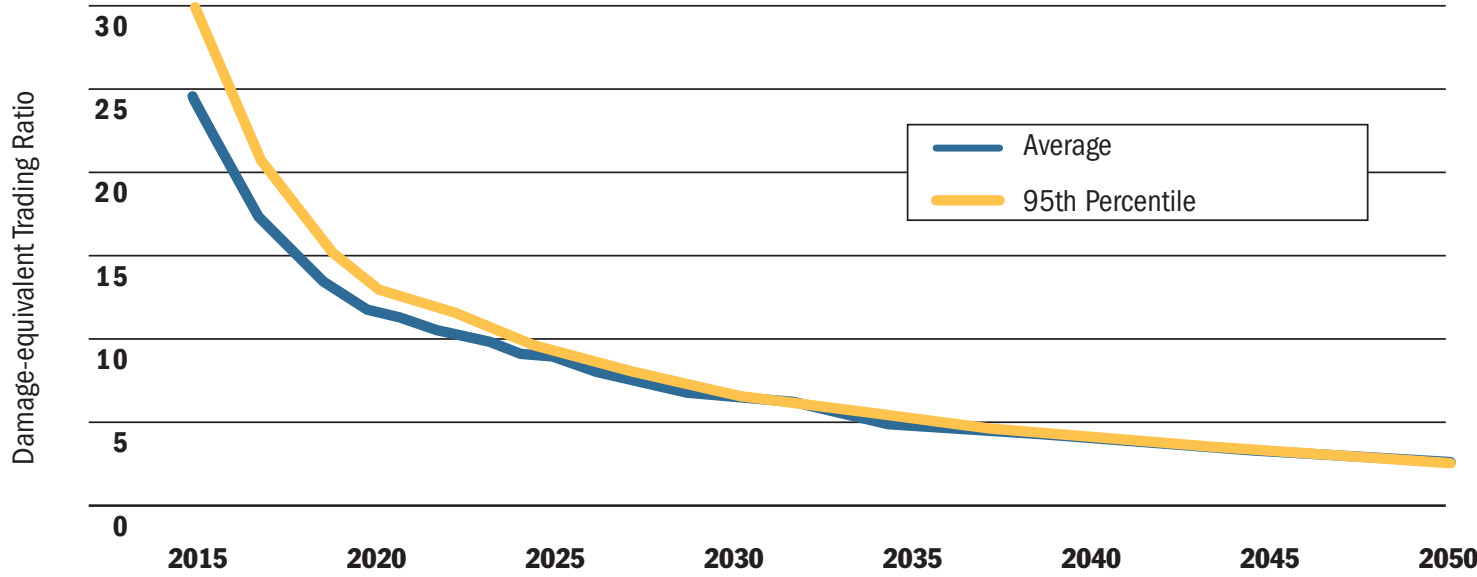

research on this relationship will be useful to determine how sensitive such results are to modeling structures and input parameter uncertainty.

\section{CONCLUSIONS AND POLICY IMPLICATIONS}

The federal interagency task force estimates of social cost of carbon suggest that it is possible to achieve permanent climate benefits from carbon storage projects that do not necessarily ensure permanent reductions or sequestration. While these estimates are, of course, sensitive to the methodologies used to calculate them-as well as to a number of assumptions about projected emissions paths, damage functions over time, economic growth paths, and other factors-it is instructive to understand the implications of non-zero temporary carbon storage values across a number of policy arenas.

A couple of broad generalizations emerge from an examination of the social cost of carbon numbers themselves. Of critical significance in most policy arenas is the fact that temporary storage value is highly sensitive to the length of storage as well as to the weighting structure used to aggregate and compare the monetized costs and benefits associated with climate change over time. Though such generalizations are intuitive, illustrating this sensitivity using available numbers highlights the importance of incorporating such considerations into policy design (in the case of sensitivity to project duration) and transparent policy decision making (in the case of discount rate selection) when dealing with issues related to temporary carbon storage.

The question of how the value of temporary storage compares to that of permanent reductions is a fundamental issue across a number of current, and contentious, policy debates. Relevant policy arenas range from carbon markets concerned with fungibility of credits for temporary storage to life-cycle analysis of the GHG content of a product whose emissions benefits or costs play out over time. This paper presents approaches to using the new social cost of carbon estimates to address such questions in the context of biological offsets and the life-cycle analysis of the GHG content of biofuels. This paper, and the methodologies it presents, is designed to advance the dialogue in these areas by clarifying the concepts involved and moving discussion beyond theoretical debate to the potential policy applications of actual estimates.

The science of carbon cost estimation, however, continues to evolve. If such estimates are to be useful in policy applications, practical mechanisms for addressing their inherent uncertainty will need to be designed. Such mechanisms, for instance, could include selection of a 
non-central estimate to represent the estimated outcome distribution in policy design. The distribution of uncertainty around estimates, and how it changes over time, is fundamental to the question of how such mechanisms will influence policy design parameters. More explicit exploration of that uncertainty, and how it changes with model structure and input parameter uncertainty structure, will be a critical element in future research efforts on temporary carbon storage value and policy design.

\section{REFERENCES}

Ackerman, F., and E.A. Stanton. 2010. "The social cost of carbon.” Stockholm Environment Institute, $17 \mathrm{pp}$. Available online at http://www.e3network.org/papers/SocialCostOfCarbon_ SEI_20100401.pdf.

Anda, J., A. Golub, and E. Strukova. 2009. "Economics of climate change under uncertainty: Benefits of flexibility.” Energy Policy 37: 1345-1355.

Bigsby, H. 2009. "Carbon banking: Creating flexibility for forest owners.” Forest Ecology and Management 257: 378-383.

Blanco, J.T., and C. Forner. 2000. "Expiring CERs: a proposal to addressing the permanence issue for LUCF projects in the CDM.” Economic and Financial Analysis Group, Ministry of the Environment, Bogotá, Colombia. FCCC/SB/2000/MISC.4/ Add.2/Rev.1, 14 September. Available online at http://unfccc.int/ resource/docs/2000/sbsta/misc08.pdf.

Boscolo, M., J.R. Vincent, and T. Panayotou. 1998. "Discounting costs and benefits in carbon sequestration projects.” Harvard Institute for International Development, Cambridge, Massachusetts, 17 pp.

Chomitz, K. 2000. "Evaluating carbon offsets from forestry and energy projects: how do they compare?” World Bank Policy Research Working Paper 2357, World Bank Development Research Group, Washington, DC, 25 pp.

Dornburg, V., and G. Marland. 2008. “Temporary storage of carbon in the biosphere does have value for climate change mitigation: a response to the paper by Miko Kirschbaum.” Mitigation and Adaptation Strategies for Global Change 13: 211-217.

Dutschke, M. 2001. "Permanence of CDM forests or nonpermanence of land use related carbon credits?” Hamburg Institute of International Economics Discussion Paper. Available online at http://ideas.repec.org/p/ags/hiiedp/26399.html.

Ebeling, J., and M. Yasue. 2008. “Generating carbon finance through avoided deforestation and its potential to create climatic, conservation and human development benefits.” Philosophical Transactions of the Royal Society B 363: 1917-1924.

Fearnside, P.M. 2002a. "Why a 100-year time horizon should be used for global warming mitigation calculations.” Mitigation and Adaptation Strategy for Global Change 7(1): 19-30.

Fearnside, P.M. 2002b. “Time preference in global warming calculations: a proposal for a unified index.” Ecological Economics 41(1): 21-31.

Fearnside, P.M. 2008. "On the value of temporary carbon: a comment on Kirschbaum.” Mitigation and Adaptation Strategy for Global Change 13: 207-210.
Fearnside, P.M., D.A. Lashof, and P. Moura-Costa. 2000. "Accounting for time in mitigating global warming through landuse change and forestry." Mitigation and Adaptation Strategies for Global Change 5: 239-270.

Federal Interagency Working Group. 2010. “Appendix 15A: Social cost of carbon for regulatory impact analysis under Executive Order 12866.” Available online at http://www2.eere.energy.gov/ buildings/appliance_standards/commercial/pdfs/sem_finalrule_ appendix15a.pdf.

Guo, J., C.J. Hepburn, R.S.J. Tol, and D. Anthoff. 2006. "Discounting and the social cost of carbon: A closer look at uncertainty.” Environmental Science and Policy 9: 205-216.

Hepburn, C.J., and P. Koundouri. 2006. "Recent advances in discounting: implications for forest economics.” Journal of Forest Economics 13: 169-189.

Herzog, H., K. Caldeira, and J. Reilly. 2003. “An issue of permanence: Assessing the effectiveness of temporary carbon storage.” Climatic Change 59: 293-310.

Hope, C. 2008. "Discount rates, equity weights and the social cost of carbon.” Energy Economics 30: 1011-1019.

IPCC (Intergovernmental Panel on Climate Change). 2007. "IPCC Fourth Assessment Report: Climate Change 2007 Synthesis Report.” Available online at http://www.ipcc.ch/publications_ and_data/publications_and_data_reports.htm\#1.

Kirschbaum, M.U.F. 2006. "Temporary carbon sequestration cannot prevent climate change.” Mitigation and Adaptation Strategies for Global Change 11: 1151-1164.

Marechal, K., and W. Hecq. 2006. "Temporary credits: A solution to the potential non-permanence of carbon sequestration in forests?" Ecological Economics 58: 699-716.Marland, G., and E. Marland. 2009. "Trading permanent and temporary carbon emissions credits: An editorial comment.” Climatic Change 95: 465-468.

Marland, E.S., K. Stellar, and G.H. Marland. 2010. “A distributed approach to accounting for carbon in wood products." Mitigation and Adaptation Strategies for Global Change 15: 71-91.

Marland, G., K. Fruit, and R. Sedjo. 2001. "Accounting for sequestered carbon: the question of permanence." Environmental Science \& Policy 4: 259-268.

Marshall, L. 2009. "Biofuels and the time value of carbon: Recommendations for GHG accounting protocols.” WRI Working Paper. World Resources Institute, Washington, DC, 13 pp. Available online at http://pdf.wri.org/working_papers/time_ value_of_carbon.pdf.

Mignone, B.K., R.H. Socolow, J.L. Sarmiento, and M. Oppenheimer. 2008. "Atmospheric stabilization and the timing of carbon mitigation.” Climatic Change 88: 251-265.

NERA. 2009. "Accounting for differences in the timing of emissions in calculating carbon emissions in calculating carbon intensity for the California Low Carbon Fuels Standard.” Report Prepared for the Renewable Fuels Association. Available online at http:// www.ethanolrfa.org/objects/documents/2410/nera_report_time_ accounting.pdf.

O’Hare, M., R.J. Plevin, J.I. Martin, A.D. Jones, A. Kendall, and E. Hopson. 2009. "Proper accounting for time increases cropbased biofuels' greenhouse gas deficit versus petroleum.” Environmental Research Letters 4: 7 pp.

Richards, K.R. 1997. "The time value of carbon in bottom-up studies." Critical Reviews in Environmental Science and Technology 27: S279-S292.

Richards, K.R. 2004. "A brief overview of carbon sequestration economics and policy.” Environmental Management 33(4): 545-558. 
Searchinger, T., R. Heimlich, R.A. Houghton, F. Dong, A. Elobeid, J. Fabiosa, S. Tokgoz, D. Hayes, and T.-H. Yu. 2008. "Use of U.S. croplands for biofuels increases greenhouse gases through emissions from land use change.” Science 319(5867): 1238-1240.

Sedjo, R.A., and G. Marland. 2003. "Inter-trading permanent emissions credits and rented temporary carbon emissions offsets: some issues and alternatives.” Climate Policy 3(4): 435-444.

Stavins, R.N., and K.R. Richards. 2005. "The cost of U.S. forestbased carbon sequestration.” Report prepared for the Pew Center on Global Climate Change. Available online at http://www. pewclimate.org/docUploads/Sequest_Final.pdf.

Stern, N. 2007. The economics of climate change. H.M. Treasury, UK. Available online at http://www.occ.gov.uk/activities/stern. htm.

Tol, R. 2003. "Is the uncertainty about climate change too large for expected cost-benefit analysis?” Climatic Change 56: 265-289.

Tol, R. 2008. "The social cost of carbon: Trends, outliers, and catastrophes.” Economics 2 (e-journal). Available online at http:// www.economics-ejournal.org/economics/journalarticles/2008-25.

Van der Werf, G.R., D.C. Morton, R.S. DeFries, J.G.J. Olivier, P.S. Kasibhatla, R.B. Jackson, G.J. Collatz, and J.T Randerson. 2009. “ $\mathrm{CO}_{2}$ emissions from forest loss." Nature Geoscience 2: 737-738.

Van Kooten, G.C., E.J. Engle, J. Manley, and T.M. Smolak. 2004. "How costly are carbon offsts? A meta-analysis of forest carbon sinks.” Department of Economics, University of Victoria, Working Paper 2004-01. Available online at http://ideas.repec. org/p/rep/wpaper/2004-01.html.

Van Kooten, G.C. 2008. "Biological carbon sequestration and carbon trading re-visited." $12^{\text {th }}$ Congress of the European Association of Agricultural Economists. Available online at http://www. springerlink.com/content/8372834132127434/fulltext.pdf.

Van Kooten, G.C. 2009. "Biological carbon sequestration and carbon trading re-visited.” Climatic Change 95: 449-463.

Weitzman, M.L. 2007. "Role of uncertainty in the economics of catastrophic climate change.” AEI-Brookings Joint Center Working Paper No. 07-11.

\section{ENDNOTES}

1. The views expressed are those of the author and should not be attributed to the Economic Research Service or to the USDA.

2. The authors use the term "carbon emissions" synonymously with "carbon dioxide emissions." The discussion throughout of carbon dioxide emissions also applies more broadly to carbon dioxide equivalent emissions.

3. Throughout this working paper we refer to the benefits of reducing emissions as the value of avoiding the social costs associated with a unit of emissions. This figure does not incorporate any consideration of the cost of curtailing emissions, and should therefore not be considered a net benefit figure. Economic theory tells us that the efficient level of regulation of carbon will be one leading to an emissions level where the marginal cost of a unit of additional abatement is equal to the social cost of carbon (i.e., where marginal costs of reduction $=$ marginal benefits of reduction).

4. Although not illustrated here, the impact horizon may also be measured relative to a fixed end point-i.e., impacts are measured through 2100, regardless of when the emission occurs. This methodology creates a truncation bias, however, where later emissions have lower impact simply because the period over which their impacts are measured is truncated (see Marshall [2009] for more detail). Such a methodology builds in a bias toward declining social costs of carbon.

5. A description of the discounting scenarios used, together with an explanation of why they were chosen, is available in the documentation of the working group's efforts and results at http://www1.eere.energy.gov/buildings/appliance_standards/ commercial/pdfs/sem_finalrule_appendix15a.pdf.

6. This result is specific to the particular relationship between SCC, growth rate of SCC, and discount rate found within these estimates. If the SCC itself is not as sensitive to the discount rate used in the first round of discounting (and is therefore more similar across discount rates), then it might be feasible to see a case where the temporary value of storage increases with the discount rate used. In such a scenario, a high discount rate decreases the perceived impact of later emissions so heavily that it increases the incentive to hold carbon in storage until later when it can be released with what is perceived to be far less damage.

7. Net emissions are the total emissions associated with producing and using the fuel minus the avoided emissions associated with not producing and using an energy-equivalent amount of fossil fuel.

8. Richards (1997) demonstrates that use of monetary or market discount rates may be appropriate under very restrictive assumptions about the shape of the marginal damage curve from carbon emissions and its relationship to atmospheric stocks.

9. Many integrated assessment models (IAMs) have a difficult time incorporating a consideration of catastrophic risk into their social cost of carbon calculations; use of an upper-tail estimate may also attempt to compensate for what is considered to be an inadequate representation of catastrophic costs. 


\section{ABOUT THE AUTHORS}

Liz Marshall is a research economist at USDA's Economic Research Service, 1800 M St., NW, Washington, DC 20036. Phone: (202) 694-5571, email: emarshall@ers.usda.gov.

Alexia Kelly conducted this research as a Senior Associate at World Resources Institute and now serves as a Climate Change Mitigation Expert at the U.S. Department of State. Phone: (202) 647-1555, email: kellyac@state.gov.

\section{ACKNOWLEDGMENTS}

WRI would like to thank the David and Lucile Packard Foundation and the Linden Trust for Conservation for support of its climate, agriculture and biofuels programs. The authors also thank John Talberth, Nicholas Bianco, and Charles Iceland of the World Resources Institute and Marc Ribaudo of USDA's Economic Research Service for their reviews and thoughtful comments.

\section{ABOUT WRI}

The World Resources Institute is an environmental think tank that goes beyond research to find practical ways to protect the earth and improve people's lives. Our mission is to move human society to live in ways that protect Earth's environment and its capacity to provide for the needs and aspirations of current and future generations. 